\title{
Phenolic Composition of Dipteryx alata Vogel Pulp + Peel and Its Antioxidant and Cytotoxic Properties
}

\author{
Érica O. Barizão, ${ }^{a}$ Joana S. Boeing, ${ }^{\circledR b}{ }^{b}$ Eliza M. Rotta, ${ }^{\oplus a}{ }^{a}$ Hélito Volpato, ${ }^{c}$ \\ Celso V. Nakamura, ${ }^{c}$ Liane Maldaner ${ }^{\circledR a}$ and Jesuí V. Visentainer ${ }^{\circledR} * a$ \\ ${ }^{a}$ Departamento de Química, Universidade Estadual de Maringá, 87020-900 Maringá-PR, Brazil \\ ${ }^{b}$ Faculdade de Ciências Exatas e Tecnologia, Universidade Federal da Grande Dourados, \\ 79804-970 Dourados-MS, Brazil \\ 'Laboratório de Inovação Tecnológica no Desenvolvimento de Fármacos e Cosméticos, \\ Universidade Estadual de Maringá, 87020-900 Maringá-PR, Brazil
}

\begin{abstract}
Dipteryx alata Vogel is a native fruit from Brazil, which has been poorly investigated concerning its phenolic composition and the biological effects of its pulp + peel. Thus, in this study we evaluated the antioxidant activity and total phenolic content of the $D$. alata pulp + peel extracts obtained with different solvents, as well as determined the phenolic compounds by ultra-high performance liquid chromatography tandem mass spectrometry (UHPLC-MS/MS) analysis. In addition, cytotoxic effects of $D$. alata pulp + peel extract on non-tumor and cancer cell lines were investigated for the first time. The results showed that phenolic compounds can be efficiently extracted from pulp + peel of D. alata by organic solvent-water mixtures as an extraction system. The developed UHPLC-MS/ MS method allowed the quantification of eighteen phenolic compounds in D. alata pulp + peel extract for the first time, which luteolin and trans-cinnamic acid were predominant. In addition, D. alata pulp + peel extract exhibited better cytotoxity against $\mathrm{SiHa}$ and $\mathrm{C} 33 \mathrm{~A}$ cervical cancer cell lines, while weak cytotoxicity was noticed against non-tumor HaCaT and L929 cell lines, pointing out its safety and providing preliminary evidence of its anticancer potential. Our findings indicate that $D$. alata pulp + peel can be explored as a natural source of phenolic compounds with promising antioxidant and cytotoxic properties.
\end{abstract}

Keywords: Cerrado fruits, baru, phenolic compounds extraction, UHPLC-MS/MS, MTT assay

\section{Introduction}

In the last decades, the health-promoting effects of fruits have attracted extensive attention from scientists worldwide. The health benefits of fruits are mainly ascribed to their antioxidant properties. ${ }^{1}$ Human cells are continuously exposed to pro-oxidants species, so, in addition to the endogenous antioxidants, dietary antioxidants have a critical role in balancing oxidation-reduction in the body and in preventing oxidative stress related disorders, such as neurodegenerative and cardiovascular diseases, diabetes and cancer. ${ }^{2,3}$

Phenolic compounds have been shown to be the most bioactive among the natural antioxidant agents and they are mainly found in fruits and vegetables. ${ }^{2}$ In this way, fruits and vegetables have been extensively studied for

*e-mail: jesuiv@gmail.com their phenolic composition, antioxidant activity and other biological properties ${ }^{4-7}$ However, some fruit species or fruit parts are still scientifically underexploited concerning their phenolic composition and potential biological action, such as Dipteryx alata Vogel pulp + peel.

Dipteryx alata Vogel is a native tree species to the Brazilian Cerrado belonging to the Fabaceae family. Its fruits are commonly known as "baru" in Brazil and they are characterized by a pulp covered by a thin brown peel (mesocarp) with a sweet taste, that envelope a single edible oleaginous seed, generally named almond. ${ }^{8,9}$ The pulp along with the peel of $D$. alata fruit can be consumed in natura; while the almond contains a trypsin inhibitor, which must be inactivated by heat treatment before consumption. ${ }^{10}$ D. alata fruits are also used for candies, cakes, sorbets, cereal bars, cookies and breads production. ${ }^{8,9}$

Studies have demonstrated the protective effect of the consumption of $D$. alata almonds on the oxidative status 
of rats supplemented orally with iron ${ }^{11}$ and of rats fed with high-fat diets. ${ }^{12}$ Moreover, clinical trials showed that diet supplementation with a $D$. alata almonds improved highdensity lipoproteins and reduced abdominal adiposity ${ }^{13}$ and increase the activity of glutathione peroxidase, an antioxidant enzyme, in overweight and obese women. ${ }^{14}$ These almonds present great nutritional value, being considered a source of minerals, proteins and unsaturated fatty acids. ${ }^{6} 10$ Also, the presence of phytosterols, terpenes, tocopherols and phenolic compounds have been reported in extracts from the of $D$. alata almonds. ${ }^{6,10,15,16}$ However, pulp and peel of $D$. alata has been poorly studied about their biological activities and/or phenolic composition, with only two studies recently published. Santiago et al. ${ }^{8}$ evaluated the proximate composition, antioxidant activity, and total phenolic content (TPC) from the extracts of peel, pulp, and raw and roasted almonds of D. alata fruit. Leite et al. ${ }^{17}$ identified the chemical composition, including the phenolic compounds, of the pulp of $D$. alata fruit, and evaluated its antioxidant activity in vitro and in vivo, its toxic effects and ability to increase the life expectancy in the nematode Caenorhabditis elegans.

Given this background, the present study aimed to evaluate the antioxidant activity and TPC of the D. alata pulp + peel extracts obtained with different solvents, as well as to determine the phenolic compounds by ultrahigh performance liquid chromatography tandem mass spectrometry (UHPLC-MS/MS) analysis. In addition, their cytotoxic effects were evaluated on human cervical and colon cancer cell lines and compared to non-tumor cell lines.

\section{Experimental}

\section{Chemicals}

Phenolic compounds standards (all with purity $\geq 95 \%$ ) of caffeic acid, chlorogenic acid, gallic acid, hydroxybenzoic acid, $p$-coumaric acid, protocatechuic acid, sinapic acid, syringic acid, trans-cinnamic acid, (-)-epicatechin, (-)-epicatechin gallate, apigenin, luteolin, myricetin, naringenin, quercetin, trans-resveratrol, and rutin were acquired from Sigma-Aldrich (St. Louis, USA), whereas ellagic, ferulic and vanillic acids were acquired from Fluka (Buchs, Switzerland). Stock standard solutions were prepared by dissolving $10 \mathrm{mg}$ of each phenolic compounds, with the exception of apigenin $(5 \mathrm{mg})$, luteolin $(4.4 \mathrm{mg})$, and rutin $(3.6 \mathrm{mg})$, in $10 \mathrm{~mL}$ of methanol and stored at $-18{ }^{\circ} \mathrm{C}$. An intermediate solution containing all standard compounds was prepared in methanol, and dilutions from this solution were done at different levels for the construction of analytical curves. HPLC-grade ethanol, methanol and formic acid were purchased from Sigma-Aldrich (St. Louis, USA). Ultrapure water was obtained from a Milli-Q ultrapure water purification system (Millipore, Burlington, USA).

Folin-Ciocalteu's phenol reagent, 2,2-azobis (2-methylpropanimidamide) dihydrochloride (AAPH), ( \pm )-6-hydroxy-2,5,7,8-tetramethylchromane-2-carboxylic acid (Trolox) and 2,2-diphenyl-1-picrylhydrazyl (DPPH') were obtained from Sigma-Aldrich (St. Louis, USA), whereas disodium fluorescein was obtained from Fluka (Buchs, Switzerland). Fetal bovine serum (FBS) and Dulbecco's modified Eagle's medium (DMEM) were obtained from Invitrogen (Carlsbad, USA) and 3-(4,5-dimethyl2-thiazolyl)-2,5-diphenyl-2H-tetrazolium bromide (MTT) was supplied by Sigma-Aldrich (St. Louis, USA).

\section{Samples}

Fresh ripe $D$. alata fruits, approximately $3.0 \mathrm{~kg}$, were collected from a farm located in Campo Grande, Mato Grosso do Sul, Brazil (20²6’34'S and 54³8'47'W), in September 2016. The ripening of the fruits was determined only visually by the color and texture. In the laboratory, the ripe fruits were washed and the pulp along with the peel were manually separated from the rest of the fruit (endocarp and almond), and then frozen and lyophilized. The dried pulp + peel was milled in a domestic grinder to obtain a homogeneous sample, vacuum-packed, and stored at $-18{ }^{\circ} \mathrm{C}$ until analysis.

Preparation of extracts

D. alata pulp + peel powder $(1.00 \pm 0.01 \mathrm{~g})$ was transferred to a $50 \mathrm{~mL}$ Falcon tube along with $10.0 \mathrm{~mL}$ of the extracting solvent, and the tube was immersed into the ultrasonic bath (Elmasonic P30H, Singen, Germany) with $320 \mathrm{~W}$ of potency and $37 \mathrm{kHz}$ of frequency. The extraction was performed at $30^{\circ} \mathrm{C}$ for $30 \mathrm{~min}$, according to Boeing et al..$^{5}$ After extraction, the solution was centrifuged at $6535 \times \mathrm{g}$ for $10 \mathrm{~min}$ and the supernatant was filtered through $0.22 \mu \mathrm{m}$ poly(tetrafluoroethene) (PTFE) syringe filters. Different solvents were used for extraction of phenolic compounds from D. alata pulp + peel. Solvents included methanol and ethanol, in the pure form (absolute) and also in mixtures with water to obtain a concentration of $80 \%(\mathrm{v} / \mathrm{v})$, aqueous methanol and aqueous ethanol. Furthermore, $100 \%$ ultrapure water $\left(\mathrm{H}_{2} \mathrm{O}\right)$ was also used.

\section{Antioxidant activity and total phenolic content}

The antioxidant activity was evaluated by DPPH radical scavenging and oxygen radical absorbance 
capacity (ORAC) assays. DPPH` scavenging activity was measured using the method described by Ma et al. ${ }^{18}$ Methanol solutions of Trolox $\left(0-2000 \mu \mathrm{mol} \mathrm{L} \mathrm{L}^{-1}\right)$ were used to prepare the analytical curve $\left(y=-2.98 \times 10^{-4} x+0.689\right.$, coefficient of determination $\left.\left(r^{2}\right)=0.995\right)$, and the results were expressed as micromoles of Trolox equivalents per gram of freeze-dried sample ( $\mu$ mol TE $\left.\mathrm{g}^{-1}\right)$. The ORAC assay was performed according to $\mathrm{Ou}$ et al. ${ }^{19}$ Trolox solutions $\left(0-50 \mu \mathrm{mol} \mathrm{L}^{-1}\right)$ were used to prepare the analytical curve $\left(y=0.261 x+2.07, \mathrm{r}^{2}=0.993\right)$, and the results were expressed as micromoles of Trolox equivalents per gram of freeze-dried sample ( $\left.\mu \mathrm{mol} \mathrm{TE} \mathrm{g}^{-1}\right)$.

The total phenolic content (TPC) of the extracts was determined according to Singleton and Rossi. ${ }^{20}$ Methanolic solutions of gallic acid $\left(0-180 \mathrm{mg} \mathrm{L}^{-1}\right)$ were used to prepare the analytical curve $\left(y=0.0058 x-0.0179, \mathrm{r}^{2}=0.993\right)$, and the results were expressed as milligrams of gallic acid equivalents per gram of freeze-dried sample ( $\left.\mathrm{mg} \mathrm{GAE} \mathrm{g}^{-1}\right)$.

\section{UHPLC-MS/MS analysis}

Chromatographic analysis was performed employing an Acquity UPLC H-Class system coupled to a Xevo TQD triple-quadrupole mass spectrometer equipped with a $\mathrm{Z}$ spray ${ }^{\mathrm{TM}}$ source (Waters, Milford, USA). The chromatographic separation was achieved using an Acquity UPLC ${ }^{\circledR}$ BEH C18 column (50 mm × $2.1 \mathrm{~mm}$, internal diameter (i.d.), $1.7 \mu \mathrm{m})$ at $30{ }^{\circ} \mathrm{C}$ and flow rate of $0.15 \mathrm{~mL} \mathrm{~min}^{-1}$. The mobile phase was composed of solvent A (ultrapure water acidified with $0.1 \%$ formic acid) and solvent B (methanol). Gradient elution was used and the organic solvent percentage was changed linearly as follows: $0 \mathrm{~min}, 10 \%$; $4 \mathrm{~min}, 70 \%$; $8 \mathrm{~min}, 100 \%$; $11 \mathrm{~min}, 50 \%$; $12.5 \mathrm{~min}, 10 \%$; $15 \mathrm{~min}, 10 \%$. The injection volume was $1.5 \mu \mathrm{L}$.

The electrospray ionization (ESI) source was operated in negative mode under the following conditions: capillary voltage, $3.0 \mathrm{kV}$; extractor voltage, $3.0 \mathrm{~V}$; source temperature, $130{ }^{\circ} \mathrm{C}$; desolvation gas temperature, $550{ }^{\circ} \mathrm{C}$; desolvation gas $\left(\mathrm{N}_{2}\right)$ flow, $700 \mathrm{~L} \mathrm{~h}^{-1}$; cone gas $\left(\mathrm{N}_{2}\right)$ flow, $50 \mathrm{~L} \mathrm{~h}^{-1}$; collision induced dissociation gas pressure (Ar), $3.00 \times 10^{-3}$ mbar. The mass spectrometer was operated in MS/MS mode using selected reaction monitoring (SRM). Precursor and product ions, associated with instrumental parameters optimized, and the retention times for the target analytes are presented in Table S1 (Supplementary Information (SI) section) and a representative chromatogram obtained from the standard mixture is shown in Figure S1 (SI section). Data were acquired and processed by MassLynx software version 4.1 (Waters, Milford, USA). ${ }^{21}$

Quantification of phenolic compounds in D. alata pulp + peel was achieved by the standard addition method, since blank samples were not available, and the results were expressed as milligram per kilogram of freeze-dried sample $\left(\mathrm{mg} \mathrm{kg}^{-1}\right)$. Limits of detection and quantification (LOD and LOQ, respectively) were estimated for each analyte considering the concentration that produced a signal-to-noise ratio equal or higher than 3 and 10 times the noise of the baseline, respectively, in a chromatogram of a non-fortified sample, after estimating the endogenous amount.

\section{Cell culture and cytotoxicity assay}

Six cell lines were used throughout this study: murine fibroblast (L929), human immortalized keratinocytes (HaCaT), human cervical cancer (C33A, SiHa, HeLa) and human colon cancer (Caco-2). The HeLa (HPV18-positive), SiHa (HPV16-positive), C33A (HPV-negative) and HaCaT cell lines were provided by Dr Luiza L. Villa (ICESP, School of Medicine, University of São Paulo/Brazil) and Dr Silvya S. Maria-Engler (Faculty of Pharmaceutical Sciences, University of São Paulo/Brazil). L929 (ATCC ${ }^{\circledR}$ $\mathrm{CCL1}^{\mathrm{TM}}$ ) and Caco-2 (ATCC ${ }^{\circledR}$ HTB-37) cell lines were supplied by the American Type Culture Collection (Manassas, USA). The cell lines were cultured with DMEM ( $\mathrm{pH}$ 7.4) supplemented with $10 \%$ (v/v) FBS and maintained in an incubator at $37{ }^{\circ} \mathrm{C}$ in a humidified atmosphere with $5 \% \mathrm{CO}_{2}$. The cell culture passage number is from the $4-6^{\text {th }}$ passage for the cytotoxicity assay.

In vitro cytotoxicity of $D$. alata hydroethanolic extract was determined by the MTT assay and the conditions employed in this assay was described by Boeing et al. ${ }^{5}$ Results were expressed as the $50 \%$ cytotoxic concentration $\left(\mathrm{CC}_{50}\right)$, defined as the extract's concentration that reduce $50 \%$ of cell viability, which were calculated by regression analysis.

\section{Statistical analysis}

Results were expressed as mean \pm standard deviation (SD). Data were submitted to analysis of variance (ANOVA) using one-way with comparison of means by Tukey's test from Statistica 7.0 software (StatSoft, Tulsa, USA). ${ }^{22}$ Differences were considered significant at $p<0.05$. All experiments were performed in triplicate $(n=3)$.

\section{Results and Discussion}

Total phenolic content and antioxidant activity

Ultrasound-assisted extraction (UAE) is a rapid, easy to use, inexpensive, safe, and eco-friendly extraction 
technique which is broadly used for the extraction of phenolic compounds from plant materials. ${ }^{23}$ Cavitation is the main mechanism of action of the UAE; this favors solvent penetration and promotes the disruption of cell walls of the matrix, resulting in the mass transfer of the intracellular content into extraction solution. ${ }^{24}$ In this study, UAE was used for extraction of phenolic compounds from D. alata pulp + peel and five extraction solvents, ultrapure water, absolute methanol, absolute ethanol, aqueous methanol $(80 \%, \mathrm{v} / \mathrm{v})$ and aqueous ethanol $(80 \%, \mathrm{v} / \mathrm{v})$, were compared in terms of TPC and antioxidant activity (DPPH ${ }^{*}$ and ORAC assays), as illustrated in Figures 1a and $1 b$, respectively.

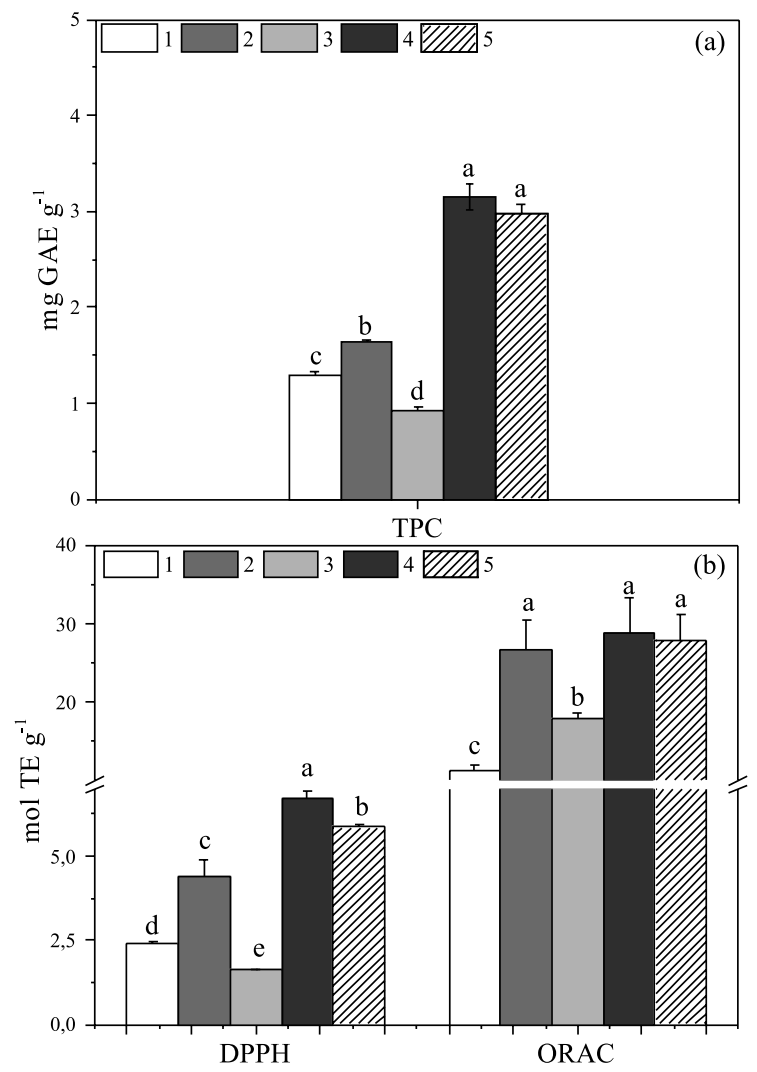

Figure 1. Comparison of total phenolic content (TPC) (a) and antioxidant activity measured by DPPH ${ }^{\cdot}$ and ORAC assays (b) of extracts of $D$. alata pulp + peel obtained with different extraction solvents. 1: ultrapure water; 2: absolute methanol; 3: absolute ethanol; 4: aqueous methanol (80\%, v/v); 5: aqueous ethanol $(80 \%, \mathrm{v} / \mathrm{v})$. Different letters between solvents represent results with statistical difference, according to the Tukey's test $(p<0.05)$.

The results showed that the TPC and antioxidant activity varied according to each solvent used in the extraction step. Overall, ultrapure water and absolute ethanol were the least favorable solvents for the extraction of the phenolic compounds from $D$. alata pulp + peel. These results are possibly associated to the differences of polarity and viscosity of the solvents used. The efficiency of ultrapure water as extraction solvent is reduced because phenolic compounds are often more soluble in organic solvents that are less polar than water. ${ }^{25}$ On the other hand, a decrease in solvent viscosity is related to better diffusion through the pores of the samples and to an increase in the propagation of ultrasonic waves in the solvent, improving the yield of the extraction. ${ }^{24}$ Ethanol is the solvent with the highest viscosity followed by water and methanol, while the increasing polarity is displayed by water $>$ methanol $>$ ethanol. Aqueous methanol $(80 \%$, $\mathrm{v} / \mathrm{v})$ and aqueous ethanol $(80 \%, \mathrm{v} / \mathrm{v})$ showed the highest values of TPC $\left(3.15 \pm 0.14\right.$ and $2.98 \pm 0.01 \mathrm{mg} \mathrm{GAE} \mathrm{g}^{-1}$, respectively) and antioxidant activity by ORAC assay $\left(28.7 \pm 4.5\right.$ and $27.9 \pm 3.2 \mu \mathrm{mol} \mathrm{TE} \mathrm{g}^{-1}$, respectively). No significant difference was observed between these extraction solvents. For DPPH ${ }^{\bullet}$ assay, aqueous methanol $(80 \%, v / v)$ showed the highest antioxidant activity with a value of $6.70 \pm 0.23 \mu \mathrm{mol} \mathrm{TE} \mathrm{g}^{-1}$ followed by aqueous ethanol $(80 \%, \mathrm{v} / \mathrm{v})$ with a value of $5.86 \pm 0.10 \mu \mathrm{mol} \mathrm{TE} \mathrm{g}^{-1}$. The polarity of the medium increases with the addition of the water to organic solvents, which facilitates the extraction of compounds that are soluble in water and/or organic solvents. ${ }^{25}$ Moreover, aqueous mixtures with organic solvents contribute to the disrupt cell walls of the matrix and dissolve the compounds at the same time. ${ }^{26}$

It is important to note that the TPC values obtained for the hydroalcoholic extracts of $D$. alata pulp + peel were higher than the values found for the methanolic extracts of raw and roasted $D$. alata almond (values ranged between

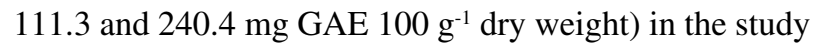
of Lemos et al. ${ }^{10}$ and aqueous extract of D. alata pulp $\left(262.089 \pm 0.60 \mathrm{mg} \mathrm{GAE} 100 \mathrm{~g}^{-1}\right) \cdot{ }^{17}$ Moreover, TPC values obtained for hydroalcoholic extracts of $D$. alata pulp along with peel were similar than values reported for the aqueous ethanol (50\%, v/v) extracts of only pulp of D. alata $(292 \mathrm{mg}$ GAE $100 \mathrm{~g}^{-1}$ of fresh weight) but lower compared to the other parts of the fruit (row and roasted almond and peel). ${ }^{8}$ The antioxidant activity by $\mathrm{DPPH}^{\circ}$ assay was higher than that found for methanolic extracts of raw and roasted D. alata almond (22.8 and $13.9 \mu \mathrm{mol} \mathrm{TE} 100 \mathrm{~g}^{-1}$ dry weight, respectively $)^{10}$ and aqueous extract of roasted $D$. alata almond $\left(0.8 \mu \mathrm{mol} \mathrm{TE} \mathrm{g} \mathrm{g}^{-1}\right.$ dry weight). ${ }^{11}$ Regarding ORAC assay, antioxidant activity of hydroalcholic extracts of D. alata pulp + peel was lower than methanolic and hydrolyzed methanolic extracts of roasted $D$. alata almond (values ranged between 88.71 and $110.44 \mathrm{mg} \mathrm{TE} \mathrm{g}^{-1}$ ) reported by Oliveira-Alves et al. ${ }^{6}$

\section{UHPLC-MS/MS analysis of phenolic compounds}

Firstly, the effect of the solvent on the extraction efficiency of the target phenolic compounds from 
pulp + peel of $D$. alata fruits was evaluated. Figure 2 presents the relation of the phenolic compounds extracted with the respective amounts (in means of peak area) for each solvent evaluated. UHPLC-MS/MS analysis showed that the phenolic compounds extracted from D. alata pulp + peel with all evaluated extraction solvents presented the same profile, with exception of ultrapure water that did not extract apigenin; however, the amounts of the individual compounds extracted varied according to the solvent employed (Figure 2). The trend of TPC and antioxidant activity analysis was comparable with that obtained by UHPLC-MS/MS analysis, where ultrapure water and absolute ethanol were the solvents that showed the lowest extraction capacity of the target phenolic compounds, followed by absolute methanol. In general, as can be observed in Figure 2, higher amounts of the phenolic compounds were obtained when aqueous ethanol $(80 \%, \mathrm{v} / \mathrm{v})$ and aqueous methanol $(80 \%, \mathrm{v} / \mathrm{v})$ were used as extraction solvents. The better efficiency of aqueous methanol or ethanol for the extraction of phenolic compounds from plant-derived samples was also reported by other authors. ${ }^{7,25}$ In this context, the use of ethanol is more recommended, especially for food matrices, due to the fact that it is non-toxic, inexpensive and not harmful to human health and to the environment. ${ }^{27}$ Therefore, aqueous ethanol $(80 \%, \mathrm{v} / \mathrm{v})$ was selected as the extraction solvent for the quantification of phenolic compounds of $D$. alata pulp + peel.

Table 1 shows the linear range of analytical curves used for the quantification of the phenolic compounds and the correlation coefficients (r), LOD and LOQ values and the concentration of phenolic compounds quantified in D. alata pulp + peel. The linearity $(r>0.99)$ for authentic reference standards, in a concentration range expected for the phenolic compounds in samples (7.5-2667 $\left.\mu \mathrm{g} \mathrm{kg}^{-1}\right)$, was satisfactory. This shows that the UHPLC-MS/MS method allows the proper quantification of the target compounds in the hydroethanolic extract of D. alata pulp + peel. Also, the LOD and LOQ were satisfactory for quantifying the target compounds at the concentration levels found in the sample. The LOD ranged from 0.03 to $100 \mu \mathrm{g} \mathrm{kg}^{-1}$, whereas LOQ ranged from 0.1 to $330 \mu \mathrm{g} \mathrm{kg}^{-1}$.

Of the twenty-one phenolic compounds analyzed in this study, eighteen of them were found and quantified in the D. alata pulp + peel, evidencing the wide range of phenolic compounds in this underexploited part of the fruit. To the best of our knowledge, the quantification of phenolic compounds in D. alata pulp + peel was not reported hitherto in the literature. Regarding the identification of phenolic compounds, a single work was recently published, in which some phenolic compounds were putatively identified in the
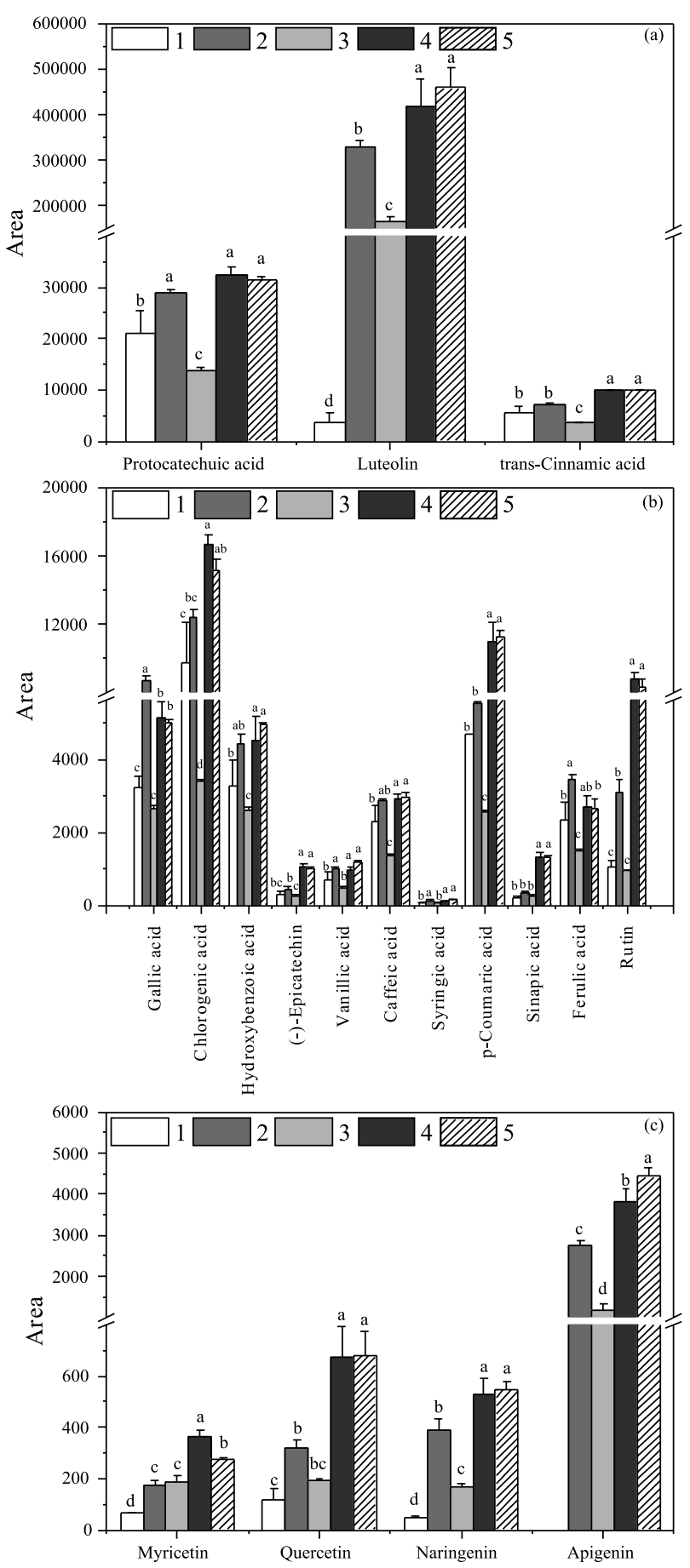

Figure 2. Effect of the solvent on the extraction of the phenolic compounds from D. alata pulp + peel. Major (a), intermediates (b) and minority (c) phenolic compounds found in the D. alata pulp + peel. 1: ultrapure water; 2: absolute methanol; 3: absolute ethanol; 4: aqueous methanol (80\%, v/v); 5: aqueous ethanol $(80 \%, \mathrm{v} / \mathrm{v})$. Different letters between solvents represent results with statistical difference, according to the Tukey's test $(p<0.05)$.

pulp of D. alata. ${ }^{17}$ In the present study, among the quantified phenolic compounds, luteolin and trans-cinnamic acid were the most abundant with concentrations of $153 \pm 1$ and $129 \pm 4 \mathrm{mg} \mathrm{kg}^{-1}$, respectively, followed by protocatechuic acid $\left(24.0 \pm 0.7 \mathrm{mg} \mathrm{kg}^{-1}\right)$. The other phenolic compounds 
Table 1. Analytical performance of the developed method and concentration of phenolic compounds from D. alata pulp + peel

\begin{tabular}{|c|c|c|c|c|c|c|}
\hline \multirow{2}{*}{ Phenolic compound } & \multirow{2}{*}{$\begin{array}{l}\text { Linear range / } \\
\left(\mu \mathrm{g} \mathrm{kg}^{-1}\right)\end{array}$} & \multicolumn{2}{|c|}{ Linear regression } & \multirow{2}{*}{$\mathrm{LOD} /\left(\mu \mathrm{g} \mathrm{kg}^{-1}\right)$} & \multirow{2}{*}{$\mathrm{LOQ} /\left(\mu \mathrm{g} \mathrm{kg}^{-1}\right)$} & \multirow{2}{*}{$\begin{array}{c}\text { Concentration }{ }^{\mathrm{a}} / \\
\left(\mathrm{mg} \mathrm{kg}^{-1}\right)\end{array}$} \\
\hline & & $y=a x+b$ & $\mathrm{r}$ & & & \\
\hline Gallic acid & $150-1200$ & $y=5544.3 x+3810.4$ & 0.9990 & 11 & 37 & $6.69 \pm 0.06$ \\
\hline Protocatechuic acid & $62.5-500$ & $y=7757.3 x+1540.1$ & 0.9963 & 10 & 33 & $24.0 \pm 0.7$ \\
\hline Hydroxybenzoic acid & $100-600$ & $y=9735 x+2939.7$ & 0.9991 & 25 & 82 & $3.00 \pm 0.02$ \\
\hline Chlorogenic acid & $400-2000$ & $y=10502 x+9194.9$ & 0.9975 & 0.13 & 0.42 & $8.8 \pm 0.1$ \\
\hline Vanillic acid & $500-2000$ & $y=909.87 x+675.55$ & 0.9959 & 84 & 277 & $7.7 \pm 0.1$ \\
\hline (-)-Epicatechin & $200-800$ & $y=2591.5 x+825.71$ & 0.9958 & 13 & 43 & $3.2 \pm 0.1$ \\
\hline Caffeic acid & $75-600$ & $y=9111.9 x+2107.7$ & 0.9957 & 7 & 23 & $2.3 \pm 0.2$ \\
\hline Syringic acid & $150-600$ & $y=512.46 x+121.08$ & 0.9927 & 21 & 69 & $2.2 \pm 0.2$ \\
\hline (-)-Epicatechin gallate & $40-240$ & $y=7395.3 x+2.24$ & 0.9957 & 2.5 & 8.2 & nd \\
\hline$p$-Coumaric acid & $150-1200$ & $y=18846 x+7633.9$ & 0.9988 & 2.4 & 7.9 & $4.09 \pm 0.05$ \\
\hline Sinapic acid & $200-800$ & $y=2353.4 x+797.18$ & 0.9929 & 34 & 113 & $3.0 \pm 0.1$ \\
\hline Ferulic acid & $250-2000$ & $y=4742.2 x+2457.1$ & 0.9951 & 0.3 & 1 & $5.0 \pm 0.2$ \\
\hline Rutin & $100-800$ & $y=22399 x+5588.8$ & 0.9988 & 0.15 & 0.5 & $2.5 \pm 0.1$ \\
\hline trans-Resveratrol & $60-360$ & $y=2397.9 x-6.93$ & 0.9940 & 5 & 17 & nd \\
\hline Ellagic acid & $100-600$ & $y=1756.9 x+17.15$ & 0.9959 & 10 & 33 & nd \\
\hline Myricetin & $10-80$ & $y=8748.3 x+218.31$ & 0.9900 & 0.2 & 0.7 & $0.25 \pm 0.03$ \\
\hline Quercetin & $12.5-100$ & $y=15540 x+614.46$ & 0.9906 & 0.2 & 0.7 & $0.40 \pm 0.02$ \\
\hline Luteolin & $292-1750$ & $y=25178 x+32313$ & 0.9960 & 0.03 & 0.1 & $153 \pm 1$ \\
\hline Naringenin & $7.5-60$ & $y=18603 x+444.25$ & 0.9956 & 0.45 & 1.5 & $0.247 \pm 0.003$ \\
\hline trans-Cinnamic acid & $667-2667$ & $y=569.32 x+621.38$ & 0.9960 & 100 & 330 & $129 \pm 4$ \\
\hline Apigenin & $40-320$ & $y=35665 x+3035$ & 0.9990 & 0.58 & 1.9 & $0.87 \pm 0.01$ \\
\hline
\end{tabular}

a Data given as the mean concentration \pm standard deviation $(n=3)$; r: correlation coefficient; LOD: limit of detection; LOQ: limit of quantification; nd: not detect.

were found in intermediate concentrations (in the range between 2.2 and $8.8 \mathrm{mg} \mathrm{kg}^{-1}$ ); while the concentration found for myricetin, quercetin, naringenin and apigenin was less than $1 \mathrm{mg} \mathrm{kg}^{-1}$. Luteolin is one of the most important bioactive flavonoids. It possesses potent biological activities, including antioxidant, anti-inflammatory, neuroprotective, anti-tumor, cardioprotective and antidiabetic activity. ${ }^{28}$ Also, trans-cinnamic acid has attracted a great deal of interest over the years because of its potential benefits to human health, including antioxidant, antifungal, antitumor, anti-malaria and anti-inflammatory activity. ${ }^{29}$ The concentration of luteolin found in D. alata pulp + peel is higher in comparison to other fruits largely consumed in Brazil, such as Euterpe precatoria $\left(21.61 \mu \mathrm{g} \mathrm{g}^{-1} \mathrm{dry}\right.$ weight $)$, Malpighia emarginata (3.16 $\mu \mathrm{g} \mathrm{g}^{-1}$ dry weight), Myrciaria dubia (3.16 $\mu \mathrm{g} \mathrm{g}^{-1}$ dry weight), and Anacardium occidentale ( $3.67 \mu \mathrm{g} \mathrm{g}^{-1}$ dry weight). ${ }^{4}$ Regarding trans-cinnamic acid, it was found in D. alata pulp at higher concentrations than in the fruits of wild plants, such as Olea europaea L. (32.43 $\mathrm{mg} \mathrm{kg}^{-1} \mathrm{dry}$ weight), Ziziphus jujuba Mill. (5.77 $\mathrm{mg} \mathrm{kg}^{-1}$ dry weight), Ficus carica $\mathrm{L}$. $\left(11.70 \mathrm{mg} \mathrm{kg}^{-1} \text { dry weight }\right)^{30}$ and also at higher levels than described for the extracts of five tropical fruits grown in Mexico, namely Annona diversifolia (2.64 $\mathrm{mg} 100 \mathrm{~g}^{-1}$ dry weight), Annona reticulata (3.54 mg $100 \mathrm{~g} \mathrm{~g}^{-1}$ dry weight), Diospyros digyna (2.07 mg $100 \mathrm{~g}^{-1}$ dry weight), Manilkara sapota L. (2.22 mg $100 \mathrm{~g}^{-1}$ dry weight) and Melicoccus bijugatus (7.27 mg $100 \mathrm{~g}^{-1}$ dry weight). ${ }^{31}$

In addition, studies describing the determination of phenolic compounds from different parts of $D$. alata fruits have been also reported in literature..$^{10,16,17,32}$ Among the phenolic compounds determined in D. alata pulp + peel extracts, several of them have already been reported for almond, bark or pulp of D. alata fruits. Lemos et al. ${ }^{10}$ identified eight phenolic compounds in raw and roasted $D$. alata almonds, with and without peels; six of which are the same as those found in $D$. alata pulp + peel extracts in our study: gallic acid, (-)-epicatechin, ferulic acid, $p$-coumaric acid, caffeic acid and hydroxybenzoic acid. In addition, quercetin, rutin, chlorogenic acid and transcinnamic acid have already been determined in raw and roasted $D$. alata almonds by Campidelli et al. ${ }^{16}$ Gallic acid was predominant in all the samples analyzed by Lemos et al. ${ }^{10}$ and Campidelli et al..${ }^{16}$ with concentrations

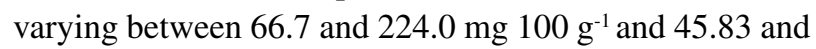


$48.90 \mathrm{mg} 100 \mathrm{~g}^{-1}$ fresh weigh, respectively. Protocatechuic and vanillic acids were isolated from barks of $D$. alata tree $^{32}$ and luteolin was also identified from $D$. alata pulp by Leite et al. ${ }^{17}$ To the best of our knowledge, syringic acid, sinapic acid, myricetin, naringenin and apigenin had not yet been determined in $D$. alata fruits.

\section{Assessment of cytotoxicity using MTT assay}

Cancer initiation and progression have been associated to oxidative stress by inducing deoxyribonucleic acid (DNA) damage and increasing DNA mutations, cell proliferation and genome instability, thereby compounds with antioxidant properties, such as phenolic compounds, could intervene with carcinogenesis. ${ }^{33}$ Considering the wide range of phenolic compounds found in D. alata pulp + peel, its hydroethanolic extract was evaluated in relation to its cytotoxic effect in non-tumor and cancer cells.

To evaluate cytotoxic effect, different concentrations of the hydroethanolic extract of D. alata pulp + peel were applied on cervical (HeLa, SiHa and C33A) and colon (Caco-2) cancer cell lines and their viability was evaluated by MTT assay. HaCaT e L929 cell lines were used as nontumor models for cytotoxic effect evaluation. The extract concentrations required to decrease $50 \%$ of the cellular viability $\left(\mathrm{CC}_{50}\right)$ are summarized in Figure 3 . The $D$. alata pulp + peel extract inhibited the viability of both cancer and non-tumor cell lines in a concentration-dependent manner (data not shown). Of the tested cell lines, the $\mathrm{SiHa}$ and C33A cells exhibited the most sensitivity toward the D. alata pulp + peel extract, with the lowest $\mathrm{CC}_{50}$ values (130 \pm 19 and $142 \pm 44 \mu \mathrm{g} \mathrm{mL}^{-1}$, respectively), followed by the HeLa cell line $\left(412 \pm 11 \mu \mathrm{g} \mathrm{mL}^{-1}\right)$. In contrast, $D$. alata pulp + peel extract showed hardly any cytotoxic effect against non-tumor $\mathrm{HaCaT}$ and $\mathrm{L} 929$ and Caco-2 cell lines, with $\mathrm{CC}_{50}$ values higher than $700 \mu \mathrm{g} \mathrm{mL}-1$. Interestingly, D. alata pulp + peel extract demonstrated tumor-cell selective potential, being less cytotoxic in non-tumor cells than in cervical cancer cells. These findings suggest that the $D$. alata pulp + peel may be a potential agent to act against cervical cancer cells. Oliveira-Alves et al. ${ }^{6}$ reported that $D$. alata almond also inhibiting cancer cell growth, in this case HT29 cell line was used as model for in vitro colon cancer studies.

The cytotoxicity of $D$. alata pulp + peel extract may be associated, at least partially, with the presence of phenolic compounds, such as luteolin and trans-cinnamic and protocatechuic acids, since it is well-known that this class of antioxidants can exert potent cytotoxic effect against different cancer cell lines., ${ }^{3,34}$ Luteolin indicated cytotoxic effect against multiple cell lines, including breast
(MDA-MB-468 and MCF-7), colorectal (HCT-116 and LoVo) and prostate (PC3 and $\mathrm{LNCaP})$ cancer cells. ${ }^{35-38}$ Previous studies $^{34,39}$ have shown that protocatechuic acid has anticancer potential, possessing apoptotic activity on human breast (MCF-7), liver (HepG2), lung (A549), cervical (HeLa) and prostate (LNCaP) cancer cell lines. Furthermore, the phenolic compounds may interact synergistically among them inducing cytotoxic effects on cancer cells.

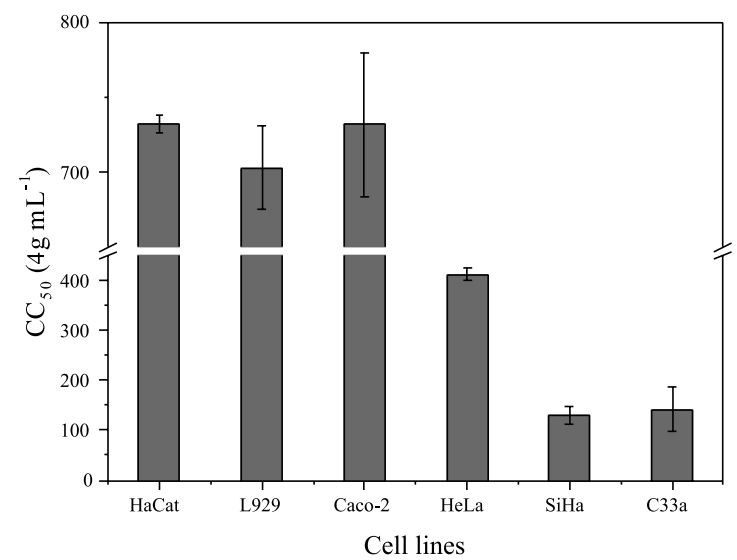

Figure 3. In vitro cytotoxicity of the hydroethanolic extract of $D$. alata pulp + peel against different non-tumor and cancer cell lines. $\mathrm{CC}_{50}$ : concentration of the extracts required to decrease $50 \%$ of the cellular viability.

\section{Conclusions}

This study provides information on the TPC, antioxidant activity by $\mathrm{DPPH}^{\circ}$ and ORAC assays, phenolic composition and cytotoxic effects on non-tumor and cancer cell lines for $D$. alata pulp + peel extracts. The results showed that antioxidant compounds, especially phenolic compounds, can be efficiently extracted from pulp + peel of D. alata by using UAE and organic solvent-water mixtures as an extraction system. The developed UHPLC-MS/MS method allowed the proper analysis of twenty-one phenolic compounds from $D$. alata pulp + peel in just $15 \mathrm{~min}$. Eighteen phenolic compounds were quantified for the first time in $D$. alata pulp + peel and the major compounds were luteolin $\left(153 \pm 1 \mathrm{mg} \mathrm{kg}^{-1}\right)$ and trans-cinnamic acid $\left(129 \pm 4 \mathrm{mg} \mathrm{kg}^{-1}\right)$. In addition, in vitro cytotoxicity, determined by the MTT assay, showed that the D. alata pulp + peel was potent against the cervical cancer cell lines ( $\mathrm{SiHa}$ and C33A). Results of the present study show that the pulp + peel of D. alata possesses promising biological potential and a wide range of phenolic compounds. Therefore, just like the almond, the pulp + peel of $D$. alata can be considered a natural source of phenolic compounds which have potential in applications for human health, such as in functional foods and in the pharmaceutical industries. 


\section{Supplementary Information}

Supplementary data are available free of charge at http://jbcs.sbq.org.br as PDF file.

\section{Acknowledgments}

The authors acknowledge the financial support provided by Conselho Nacional de Desenvolvimento Científico e Tecnológico (CNPq), Coordenação de Aperfeiçoamento de Pessoal de Nível Superior (CAPES) and Fundação Araucária de Apoio ao Desenvolvimento Científico e Tecnológico do Paraná.

\section{Author Contributions}

Érica O. Barizão was responsible for conceptualization, formal analysis, investigation, methodology, project administration and writing original draft; Joana S. Boeing for investigation and writing review and editing; Eliza M. Rotta for investigation and formal analysis; Hélito Volpato for investigation and formal analysis; Celso V. Nakamura for resources and writing review and editing; Liane Maldaner for conceptualization, supervision and writing review and editing; Jesuí $\mathrm{V}$. Visentainer for funding acquisition and supervision.

\section{References}

1. Liu, R. H.; Adv. Nutr. 2013, 4, 384.

2. Septembre-Malaterre, A.; Remize, F.; Poucheret, P.; Food Res. Int. 2018, 104, 86

3. Roleira, F. M. F.; Tavares-da-Silva, E. J.; Varela, C. L.; Costa, S. C.; Silva, T.; Garrido, J.; Borges, F.; Food Chem. 2015, 183, 235.

4. Bataglion, G. A.; da Silva, F. M. A.; Eberlin, M. N.; Koolen, H. H. F.; Food Chem. 2015, 180, 280.

5. Boeing, J. S.; Barizão, E. O.; Rotta, E. M.; Volpato, H.; Nakamura, C. V.; Maldaner, L.; Visentainer, J. V.; Food Anal. Methods 2020, 13, 61.

6. Oliveira-Alves, S. C.; Pereira, R. S.; Pereira, A. B.; Ferreira, A.; Mecha, E.; Silva, A. B.; Serra, A. T.; Bronze, M. R.; Food Res. Int. 2020, 131, 109026.

7. Nicácio, A. E.; Rotta, E. M.; Boeing, J. S.; Barizão, E. O.; Kimura, E.; Visentainer, J. V.; Maldaner, L.; Food Anal. Methods 2017, 10, 2718.

8. Santiago, G. L.; Oliveira, I. G.; Horst, M. A.; Naves, M. M. V.; Silva, M. R.; Food Sci. Technol. 2018, 38, 244.

9. Freitas, D. G. C.; Takeiti, C. Y.; Godoy, R. L. O.; Ascheri, J. L. R.; Carvalho, C. W. P.; Souza, P. L. M.; Ribeiro, A. E. C.; Ascheri, D. P. R.; Acta Hortic. 2014, 1040, 89.
10. Lemos, M. R. B.; Siqueira, E. M. A.; Arruda, S. F.; Zambiazi, R. C.; Food Res. Int. 2012, 48, 592.

11. Siqueira, E. M. A.; Marin, A. M. F.; Cunha, M. S. B.; Fustinoni, A. M.; Sant'Ana, L. P.; Arruda, S. F.; Food Res. Int. 2012, 45, 427.

12. Fernandes, D. C.; Alves, A. M.; Castro, G. S. F.; Jordao Jr., A. A.; Naves, M. M. V.; J. Food Res. 2015, 4, 38.

13. Souza, R. G. M.; Gomes, A. C.; Castro, I. A.; Mota, J. F.; Nutrition 2018, 55-56, 154

14. de Souza, R. G. M.; Gomes, A. C.; Navarro, A. M.; Cunha, L. C.; Silva, M. A. C.; Junior, F. B.; Mota, J. F.; Nutrients 2019 , 11,1750 .

15. Marques, F. G.; Oliveira Neto, J. R.; Cunha, L. C.; Paula, J. R.; Bara, M. T. F.; Rev. Bras. Farmacogn. 2015, 25, 522.

16. Campidelli, M. L. L.; Carneiro, J. D. S.; Souza, E. C.; Magalhães, M. L.; Nunes, E. E. C.; Faria, P. B.; Franco, M.; Vilas Boas, E. V. B.; Grasas Aceites 2020, 71, 343.

17. Leite, N. R.; Araújo, L. C. A.; Rocha, P. S.; Agarrayua, D. A.; Ávila, D. S.; Carollo, C. A.; Silva, D. B.; Estevinho, L. M.; Souza, K. P.; Santos, E. L.; Biomolecules 2020, 10, 1106.

18. Ma, X.; Wu, H.; Liu, L.; Yao, Q.; Wang, S.; Zhan, R.; Xing, S.; Zhou, Y.; Sci. Hortic. 2011, 129, 102.

19. Ou, B.; Hampsch-Woodill, M.; Prior, R. L.; J. Agric. Food Chem. 2001, 49, 4619.

20. Singleton, V. L.; Rossi, J. A.; Am. J. Enol. Vitic. 1965, 16, 144.

21. MassLynx software, version 4.1; Waters, Milford, MA, USA, 2005.

22. Statistica software, version 7.0; StatSoft, Tulsa, OK, USA, 2004.

23. Pudziuvelyte, L.; Jakštas, V.; Ivanauskas, L.; Laukevičienė, A.; Ibef, C. F. D.; Kursvietieneg, L.; Bernatoniene, J.; Ind. Crops Prod. 2018, 120, 286.

24. Sumere, B. R.; Souza, M. C.; Santos, M. P.; Bezerra, R. M. N.; Cunha, D. T.; Martinez, J.; Rostagno, M. A.; Ultrason. Sonochem. 2018, 48, 151.

25. Socaci, S. A.; Fărcaş, A. C.; Diaconeasa, Z. M.; Vodnar, D. C.; Rusu, B.; Tofană, M.; J. Cereal Sci. 2018, 80, 180.

26. Lao, F.; Giusti, M. M.; J. Cereal Sci. 2018, 80, 87.

27. Oroian, M.; Escriche, I.; Food Res. Int. 2015, 74, 10.

28. Nabavi, S. F.; Braidy, N.; Gortzi, O.; Sobarzo-Sanchez, E.; Daglia, M.; Skalicka-Wozniak, K.; Nabavi, S. M.; Brain Res. Bull. 2015, 119, 1.

29. Letsididi, K. S.; Lou, Z.; Letsididi, R.; Mohammed, K.; Maguy, B. L.; LWT-Food Sci. Technol. 2018, 94, 25.

30. Ahmad, N.; Zuo, Y.; Lu, X.; Anwar, F.; Hameed, S.; Food Chem. 2016, $190,80$.

31. Can-Cauich, C. A.; Sauri-Duch, E.; Betancur-Ancona, D.; Chel-Guerrero, L.; González-Aguilar, G. A.; Cuevas-Glory, L. F.; Pérez-Pacheco, E.; Moo-Huchin, V. M.; J. Funct. Foods 2017, 37, 501.

32. Puebla, P.; Oshima-Franco, Y.; Franco, L. M.; Santos, M. G.; Silva, R. V.; Rubem-Mauro, L.; Feliciano, A. S.; Molecules 2010, 15, 8193. 
33. Mileo, A. M.; Miccadei, S.; Oxid. Med. Cell. Longevity 2016, 2016, 6475624 .

34. Zheng, R.; Su, S.; Li, J.; Zhao, Z.; Wei, J.; Fu, X.; Liu, R. H.; Ind. Crops Prod. 2017, 107, 360.

35. Wilsher, N. E.; Arroo, R. R.; Matsoukas, M.; Tsatsakis, A. M.; Spandidos, D. A.; Androutsopoulos, V. P.; Food Chem. Toxicol. 2017, 110, 383.

36. Yuan, L.; Tingyuan, L.; Bingwei, J.; Feng, C.; Yi, Z.; Beuerman, R. W.; Lei, Z.; Zhiqi, Z.; J. Proteomics 2017, 161, 1.
37. Han, K.; Meng, W.; Zhang, J.; Zhou, Y.; Wang, Y.; Su, Y.; Lin, S.; Gan, Z.; Sun, Y.; Min, D.; OncoTargets Ther. 2016, 9, 3085.

38. Park, S.; Park, H. S.; Lee, J. H.; Chi, G. Y.; Kim, G.; Moon, S.; Chang, Y.; Hyun, J.; Kim, W.; Choi, Y. H.; Food Chem. Toxicol. 2013, 56, 100.

39. Yin, M.; Lin, C.; Wu, H.; Tsao, S.; Hsu, C.; J. Agric. Food Chem. 2009, 57, 6468.

Submitted: January 20, 2021

Published online: August 6, 2021 